\title{
Evidence that a complex of SIR proteins interacts with the silencer and telomere- binding protein RAP1
}

\author{
Paolo Moretti, Katie Freeman, Lavanya Coodly, and David Shore ${ }^{1}$ \\ Department of Microbiology, Columbia University College of Physicians \& Surgeons, New York, New York 10032 USA
}

\begin{abstract}
The maintenance of transcriptional silencing at HM mating-type loci and telomeres in yeast requires the SIR2, SIR3, and SIR4 proteins, none of which appear to be DNA-binding proteins. Here we show that SIR3 and SIR4 interact with a carboxy-terminal domain of the silencer, telomere, and UAS-binding protein RAP1. We identified SIR3 and SIR4 in a two-hybrid screen for RAP1-interacting factors and showed that SIR3 interacts both with itself and with SIR4. The interaction between RAP1 and SIR3 can be observed in vitro in the absence of other yeast proteins. Consistent with the notion that native SIR proteins interact with the RAP1 carboxyl terminus, we show that mutation of the endogenous SIR3 and SIR4 genes increases transcriptional activation by LexA/RAP1 hybrids. To test the importance of the RAP1-SIR3 interaction for silencing, we identified mutations in the RAP1 carboxyl terminus that either diminish or abolish this interaction. When introduced into the native RAP1 protein, these mutations cause corresponding defects in silencing at both $H M R$ and telomeres. We propose that RAP1 acts in the initiation of transcriptional silencing by recruiting a complex of SIR proteins to the chromosome via protein-protein interactions. These data are consistent with a model in which SIR3 and SIR4 play a structural role in the maintenance of silent chromatin and indicate that their action is initiated at the silencer itself.
\end{abstract}

[Key Words: Transcriptional silencing; transcriptional activation; mating type; telomere position effect; SIR proteins; protein-protein interactions]

Received June 6, 1994; revised version accepted August 12, 1994.

In the yeast Saccharomyces cerevisiae, the RAP1 gene encodes an essential regulatory protein that functions as both an activator and repressor of transcription (Shore and Nasmyth 1987; Kurtz and Shore 1991; Sussel and Shore 1991; Kyrion et al. 1993). RAP1 DNA-binding sites have been identified within the promoter elements of a large number of genes, including most ribosomal protein genes and a number of glycolytic enzyme genes. In cases where deletion analyses have been performed, these RAP1-binding sites behave as upstream activation sites (UASs) (Rotenberg and Woolford 1986; Vignais et al. 1987; Buchman et al. 1988b; Chambers et al. 1989; Nishizawa et al. 1989; Bitter et al. 1991). Conversely, RAP1binding sites at the HMR-E and HML-E silencers are required for complete repression of mating-type genes at the HMR and HML loci (Brand et al. 1987; Kimmerly et al. 1988; Mahoney et al. 1991; McNally and Rine 1991). At telomeres, multiple RAP1-binding sites are found within the terminal poly $\left(\mathrm{C}_{1-3} \mathrm{~A}\right)$ repeats (Longtine et al. 1989; Gilson et al. 1993), where the protein is involved in both the regulation of telomere structure and telomeric silencing (Conrad et al. 1990; Lustig et al. 1990; Sussel and Shore 1991; Kyrion et al. 1992, 1993).

\footnotetext{
${ }^{1}$ Corresponding author.
}

Several lines of evidence indicate that RAP1 is a context-dependent regulator. First, the specific sequence of a RAPl-binding site does not determine its regulatory function: Silencer-associated sites can function to activate transcription when placed within promoters and vice versa (Shore and Nasmyth 1987). Second, in both silencer and promoter contexts, RAP1 usually requires other regulatory proteins bound nearby to execute its proper function. For example, it appears that the juxtaposition of a RAPl-binding site with an autonomously replicating sequence (ARS) consensus element (ACS) and an ABF1-binding site can constitute a silencer element (McNally and Rine 1991). A complex of six proteins called the origin recognition complex (ORC) binds to the ACS and cooperates with RAPI at silencers (Bell et al. 1993; Foss et al. 1993; Micklem et al. 1993). At several glycolytic gene promoters the activator protein GCR1 has been shown to bind near RAPl and contribute to the activation of these genes (Baker 1991; Huie et al. 1992).

Two types of experiments indicate that the activation and silencing functions of RAPl are at least in part encoded by genetically separable domains of the protein. Missense mutations ( $\left.\mathrm{rap} 1^{s}\right)$ have been identified in a carboxy-terminal region of $R A P 1$ that lead to defects in silencing but do not affect activation (Sussel and Shore 
1991). In a different approach, GAL4 DNA-binding domain $\left(G_{B D}\right) / R A P 1$ hybrid proteins have been used to map both activation and silencing domains within RAP1 (Hardy et al. 1992a). A carboxy-terminal region of RAP1 (amino acids 630-695), just beyond a centrally located DNA-binding domain, activates transcription in the context of $\mathrm{G}_{\mathrm{BD}} / \mathrm{RAP1}$ hybrids, whereas overexpression of the last 150 amino acids of the protein (678-827) can interfere with silencing, suggesting that this domain may play a role in silencing in the context of the native protein.

To explain how RAPl might work as a context-dependent regulator, we proposed that when the carboxy-terminal domain is bound to a silencer it interacts specifically with factor(s) involved in repression. Alternatively, when bound to a promoter, we imagine that the adjacent activation region functions to stimulate transcription, either by interacting directly with the basal transcriptional machinery or through interactions with coactivators (Hardy et al. 1992a). The inhibition of silencing brought about by the overexpression of the RAP1 carboxyl terminus could be accounted for by the titration ("squelching") of a RAP1-interacting factor involved in repression. To begin to test these ideas, we employed a strongly derepressing $\mathrm{G}_{\mathrm{BD}} / \mathrm{RAPl}$ hybrid in the two-hybrid system (Fields and Song 1989; Chien et al. 1991) and identified a new yeast gene, RIF1 (RAP1 interacting factor 1) (Hardy et al. 1992b). A deletion of the RIF1 gene results in derepression of an $H M R-E$ silencer, whose ARS element has been deleted, and in the elongation of telomeres. These two phenotypes are characteristic of silencing-defective rap $1^{s}$ mutants and lead to the suggestion that one function of RAP1 is to direct the binding of RIF1 to silencers and telomeres (Hardy et al. 1992b). However, RIF1 is only required for silencing at $H M R$ when the A site (an ARS consensus element) is deleted from the HMR-E silencer, whereas the RAPl-binding site is required for full repression under all circumstances tested, suggesting that RIFl might not be the only RAPl-interacting protein involved in silencing.

Several trans-acting factors, in addition to RIF1 and the known silencer-binding proteins ORC, RAP1, and ABF1 (Shore et al. 1987; Buchman et al. 1988a) are involved in the repression of $H M$ loci and telomeres. Three SIR (silent information regulator) genes (SIR2, SIR3, and $S I R 4$ ) are required to maintain the repressed state (Haber and George 1979; Klar et al. 1979; Rine et al. 1979; Rine and Herskowitz 1987; Aparicio et al. 1991), and SIR1 is important in the establishment of repression at $H M$ loci (Pillus and Rine 1989; Chien et al. 1993). Although all four of these SIR genes have been cloned and sequenced (Shore et al. 1984; Ivy et al. 1986; Marshall et al. 1987; Stone et al. 1991), the precise role of their gene products in silencing remains unknown. None of the SIR proteins appears to bind DNA directly.

To test the possibility that the SIR proteins might work in part by interacting directly with RAPl, we extended our previous screen for RAPl-interacting proteins, in this case using fusions between the bacterial DNA-binding protein LexA and the carboxyl terminus of
RAP1. This new two-hybrid screen identified SIR3 and SIR4 as RAPl-interacting factors. In direct tests using the two-hybrid system we also show that SIR3 can interact with itself and with SIR4. We demonstrate that SIR3 can bind to RAP1 in vitro in the absence of other yeast proteins. In support of the idea that the endogenous SIR proteins interact with the RAPl carboxyl terminus, we show that mutations in three SIR genes (SIR2, SIR3, and $S I R 4)$ and $R I F 1$ increase the activation potential of LexA/RAPl hybrid proteins when these hybrids contain an intact RAPl carboxyl terminus. We also show that the RAP1-SIR3 interaction does not require the native SIR1-4 genes, and is improved by mutation of RIF1. Finally, we demonstrate that mutations in RAPl that diminish SIR3 binding in the two-hybrid system cause defects in silencing at both $H M$ loci and telomeres when incorporated into the native RAP1 gene. These results suggest that silencing is initiated by direct protein-protein interactions at the RAPl carboxyl terminus that recruit SIR3 and SIR4 to DNA.

\section{Results}

Identification of SIR3 and SIR4 as RAP1-interacting factors using the two-hybrid system

Previous studies using the two-hybrid system indicated that the RIFl protein interacts with the carboxyl terminus of RAPl (Hardy et al. 1992b). In an attempt to determine whether SIR proteins are also able to interact with this domain of RAP1, we extended our previous screen. RIF1 was isolated from a library generated by partial Sau3A digestion of total yeast genomic DNA inserted into the pGAD2 vector (Chien et al. 1991). We therefore screened the two other reading frame libraries (in the pGAD1 and pGAD3 vectors), using a slightly longer RAP1 hybrid [LexA/RAPl(635-827)] and the reporter strain CTY10-5D (see Materials and methods). From $\sim 200,000$ independent transformants, $>30$ clones were isolated that activated the reporter gene in a LexA/ RAPl(635-827)-dependent manner. Southern blotting and partial DNA sequence analysis revealed that RIF1 had not been reisolated in either of these screens and indicated that two clones contained parts of the SIR3 and SIR4 genes.

The $\mathrm{G}_{\mathrm{AD}} / \mathrm{SIR} 3$ clone that we isolated encodes the carboxy-terminal two-thirds of SIR3 (from amino acids 307 to 978 ) fused in-frame to the $G_{A D}$-coding sequences. It is worth noting that this hybrid does not contain the amino acids affected in SIR3 suppressor mutations that restore silencing in histone $\mathrm{H} 4$ (HHF2) mutant strains (Johnson et al. 1990). The $\mathrm{G}_{\mathrm{AD}} / \mathrm{SIR} 4$ clone contains only the carboxy-terminal $11 \%$ of the protein (from amino acids 1204 to 1358 ), also fused in-frame to $\mathrm{G}_{\mathrm{AD}}$-coding sequences. This small carboxy-terminal fragment of SIR4 is sufficient to allow self-association as judged by the two-hybrid system (Chien et al. 1991).

Table 1 shows that both $\mathrm{G}_{\mathrm{AD}} / \mathrm{SIR} 3$ and $\mathrm{G}_{\mathrm{AD}} / \mathrm{SIR} 4$ require that RAP1 sequences be fused to LexA for activation to occur, as they fail to activate with either LexA 
Table 1. Identification of SIR3 and SIR4 as RAP1-interacting proteins by the two-hybrid system

\begin{tabular}{|c|c|c|}
\hline \multicolumn{2}{|c|}{ Hybrid } & \multirow{2}{*}{$\begin{array}{l}\text { Transcriptional } \\
\text { activation }^{\mathbf{a}}\end{array}$} \\
\hline DNA-binding domain & activation domain & \\
\hline $\begin{array}{l}\text { LexA/RAP1 }(635-827) \\
\text { LexA } \\
\text { LexA/RAP1 }(635-827) \\
\text { LexA/RAP1 }(635-827)\end{array}$ & $\begin{array}{l}\mathrm{G}_{\mathrm{AD}} / \mathrm{SIR} 3(307-978) \\
\mathrm{G}_{\mathrm{AD}} / \mathrm{SIR} 3(307-978) \\
\mathrm{G}_{\mathrm{AD}} \\
\text { SIR3-2 } 2\end{array}$ & $\begin{array}{c}++ \\
- \\
- \\
-\end{array}$ \\
\hline $\begin{array}{l}\text { LexA/RAP1 }(635-827) \\
\text { LexA } \\
\text { LexA/RAPl }(635-827) \\
\text { LexA/RAPl }(635-827)\end{array}$ & $\begin{array}{l}\mathrm{G}_{\mathrm{AD}} / \mathrm{SIR} 4(1204-1358) \\
\mathrm{G}_{\mathrm{AD}} / \mathrm{SIR} 4(1204-1358) \\
\mathrm{G}_{\mathrm{AD}} \\
\mathrm{SIR} 4-2 \mu\end{array}$ & $\begin{array}{l}+ \\
- \\
- \\
-\end{array}$ \\
\hline
\end{tabular}

a $+++\mid$ Signal (strong blue color) detected in $\sim 3-5 \mathrm{hr}$ in $\beta$-gal assay on nitrocellulose filters; $(+)$ signal detected after $8-12 \mathrm{hr}$ of incubation; (-) no signal detected after $24 \mathrm{hr}$ of incubation.

alone or a LexA/lamin fusion (data not shown) that appears to interact nonspecifically with a number of different pGAD hybrids (R. Sternglanz and S. Fields, pers. comm.). We were concerned that the effect of either $\mathrm{G}_{\mathrm{AD}}$ /SIR hybrid might be attributable to a dominantnegative effect on SIR function brought about by overexpression of the SIR protein. To test this idea we overexpressed both SIR3 and SIR4 by placing their genes on high-copy vectors. In neither case did we observe activation by LexA/RAP1(635-827), suggesting that activation requires the $G_{A D}$ sequences and probably results from a RAPl-SIR interaction.

The SIR3 protein interacts with itself and SIR4 in the two-hybrid system

Previous genetic studies have suggested that the SIR3 and SIR4 proteins might interact with each other (Ivy et al. 1986; Marshall et al. 1987). In addition, SIR4 has been shown to interact with itself in the two-hybrid system (Chien et al. 1991). We thus decided to use this method to ask directly whether SIR3 and SIR4 can interact with each other and whether SIR3 can self-associate as does SIR4. Two LexA/SIR3 fusions were constructed, one coding for nearly the full-length SIR3 protein lamino acids 2-978) and the other for the carboxy-terminal twothirds of SIR3 (amino acids 307-978). This shorter hybrid contains the same region of SIR3 that is fused to the activation domain of GAL4 in the clone isolated from the pGAD1 fusion library. Using the $\mathrm{G}_{\mathrm{AD}} / \mathrm{SIR} 3$ and $\mathrm{G}_{\mathrm{AD}} / \mathrm{SIR} 4$ clones isolated from the library screen, we were able to demonstrate a specific interaction with both LexA/SIR3 hybrids (Table 2). The shorter LexA/SIR3 hybrid appeared to interact more strongly than the larger hybrid with both $\mathrm{G}_{\mathrm{AD}}$ /SIR3 and $\mathrm{G}_{\mathrm{AD}}$ /SIR4. We have not investigated the cause of this difference, which might be attributable to differences in protein stability or folding, or to an inhibitory effect of the SIR3 amino terminus. In the same experiment, $\mathrm{G}_{\mathrm{AD}} / \mathrm{RIF1}$ was tested and no interaction with SIR3 was detected (data not shown). The interaction between SIR3 and SIR4 was confirmed by constructing two LexA/SIR4 fusions, coding for $33 \%$ or $7 \%$ of the carboxyl terminus of SIR4, corresponding to the GAL4 DNA-binding domain fusions used previously to demonstrate SIR4 self-association (Chien et al. 1991). Both of these LexA/SIR4 hybrids interact strongly with the $\mathrm{G}_{\mathrm{AD}} / \mathrm{SIR} 3(307-978$ ) clone (Table 2). These results demonstrate that the carboxyl termini of SIR3 and SIR4 can interact with each other, as well as with RAP1. The formation of both homodimers and heterodimers for higher multimers) by SIR3 and SIR4 suggests that these two proteins may form a complex containing at least four subunits.

\section{SIR3 binds to RAP1 in vitro}

To ask whether the SIR3 protein can interact directly with RAPl we used an in vitro protein-binding assay. Sequences encoding the carboxyl terminus of RAPl were fused to the glutathione $S$-transferase (GST) gene, and the resulting hybrid proteins were expressed in Escherichia coli and partially purified by binding to glutathione-agarose beads. As a source of SIR3 protein the entire SIR3-coding sequence was transcribed in vitro using T7 polymerase and translated in vitro using a rabbit reticulocyte lysate in the presence of ${ }^{35} \mathrm{~S}$-labeled methionine (see Materials and methods for details). Labeled SIR3 pro-

Table 2. SIR3-SIR3 and SIR3-SIR4 interactions detected by the two-hybrid system

\begin{tabular}{|c|c|c|}
\hline \multicolumn{2}{|c|}{ Hybrid } & \multirow{2}{*}{$\begin{array}{l}\text { Activation } \\
(\beta \text {-gal Units })\end{array}$} \\
\hline DNA-binding domain & activation domain & \\
\hline LexA/SIR3 (2-978) & $\mathrm{G}_{\mathrm{AD}}$ & 3.0 \\
\hline LexA/SIR3 (2-978) & $\mathrm{G}_{\mathrm{AD}} / \mathrm{SIR} 3(307-978)$ & 49 \\
\hline LexA/SIR3 (2-978) & $\mathrm{G}_{\mathrm{AD}} / \mathrm{SIR} 4(1204-1358)$ & 77 \\
\hline LexA/SIR3 (307-978) & $\mathrm{G}_{\mathrm{AD}}$ & 3.0 \\
\hline LexA/SIR3 (307-978) & $\mathrm{G}_{\mathrm{AD}} / \mathrm{SIR} 3(307-978)$ & 1066 \\
\hline LexA/SIR3 (307-978) & $\mathrm{G}_{\mathrm{AD}} / \mathrm{SIR} 4(1204-1358)$ & 1938 \\
\hline LexA/SIR4 (839-1358) & $\mathrm{G}_{\mathrm{AD}}$ & 5 \\
\hline LexA/SIR4 (839-1358) & $\mathrm{G}_{\mathrm{AD}} / \mathrm{SIR} 3(307-978)$ & 1171 \\
\hline LexA/SIR4 (1252-1358) & $\mathrm{G}_{\mathrm{AD}}$ & 49 \\
\hline LexA/SIR4 (1252-1358) & $\mathrm{G}_{\mathrm{AD}} / \mathrm{SIR} 3(307-978)$ & 591 \\
\hline
\end{tabular}


tein was incubated with a set of GST/RAP1 hybrid proteins bound to glutathione-agarose beads. After the beads were washed, bound proteins were eluted and analyzed by SDS-PAGE and autoradiography. As shown in Figure 1, SIR3 protein is able to interact with GST/RAP1 fusions with amino-terminal endpoints between amino acids 562 and 653 . (The genetic properties of the corresponding LexA/RAP1 hybrids are described in detail below.) We believe that these interactions are specific because binding is dependent on RAPl sequences, and labeled RAP1 protein, tested in the same conditions, fails to bind to the GST/RAP1 hybrids (Fig. 1). In our assay conditions binding by SIR3 is more efficient with the longer GST/RAP1 fusion proteins, but an interaction is detectable with the shorter hybrids. These results indicate that the SIR3 protein can interact physically with the carboxyl terminus of RAP1 in the absence of other yeast proteins. So far, we have been unable to detect an interaction in vitro between the RAP1 carboxyl terminus and SIR4. Consequently, we do not know whether the interaction detected in vivo is direct.

\section{RAP1 sequences required for interaction with SIR3, SIR4, and RIF1}

A series of LexA/RAP1 constructs with different RAP1 fusion points (between amino acids 635 and 702) was used to determine the amino-terminal boundary of RAP1 sequences required for the interaction with SIR3, SIR4, and RIFl. The primary conclusion to be drawn from these experiments (see Fig. 2) is that amino acids 679827 of RAPl are sufficient for the interaction with both

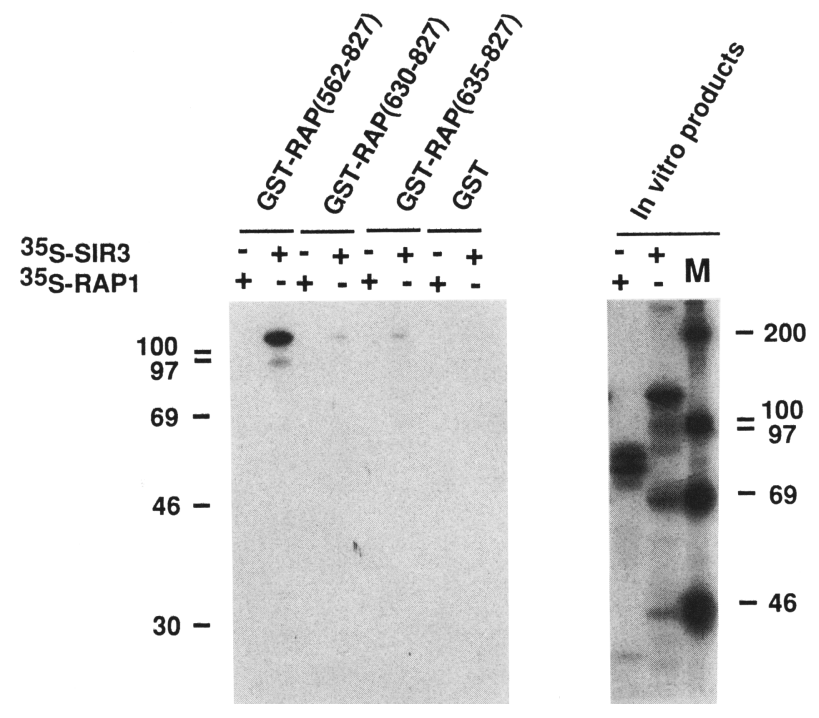

Figure 1. SIR3 binds to GST/RAPl hybrid proteins in vitro. (See Materials and methods for details of the binding assay.) (Right) The in vitro-produced labeled proteins (from a different gel) before addition to the GST/RAPl agarose beads. The primary, high-molecular-weight translation product in the SIR3 lane has the same mobility as the material bound to the GST/ RAP1 beads (left).
DNA Binding Domain Hybrid

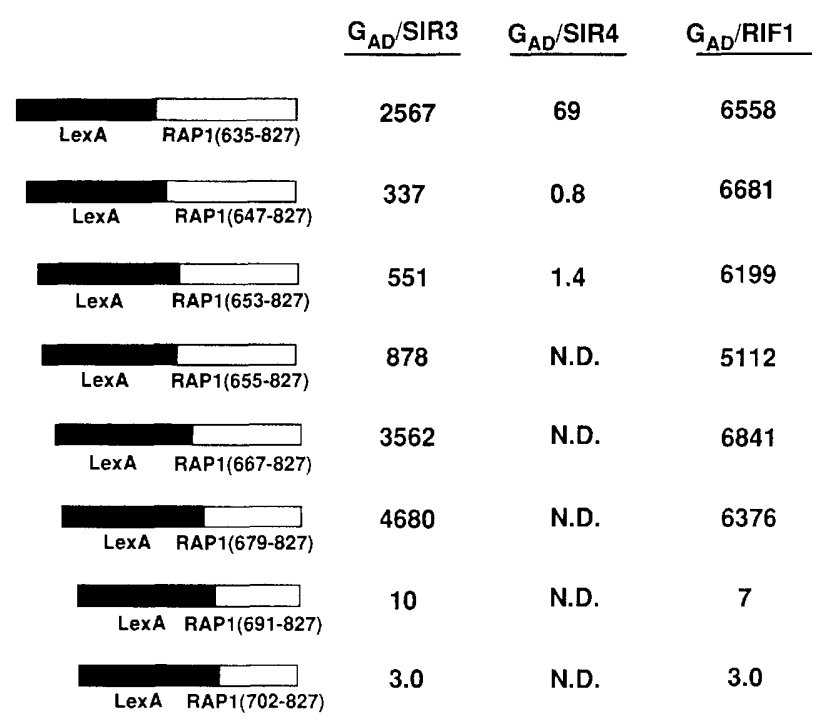

Figure 2. Interaction of $\mathrm{G}_{\mathrm{AD}} / \mathrm{SIR} 3(307-978), \mathrm{G}_{\mathrm{AD}} / \mathrm{SIR} 4(1204$ 1358), and $G_{A D} / R I F 1(1614-1916)$ with a series of LexA/RAP1 hybrids in the two-hybrid system. None of the LexA/RAPl hybrids used in this experiment are transcriptional activators. $\beta$-Gal levels for the interaction of $G_{A D} / S I R 4$ with the bottom five LexA/RAPl hybrids were tested by the X-gal filter assay (see Materials and methods) and were all found to be negative.

SIR3 and RIF1. However, SIR4 is able to interact only with the LexA/RAP1(635-827) hybrid. All of the hybrids that interact with RIFl appear to do so with equal strength ( $\beta$-galactosidase level of $\sim 5000-7000$ units). In contrast, the interaction between SIR3 and this same set of LexA/RAP1 hybrids varies in a manner not strictly related to the length of RAPl sequences present. For example, the RAP1-SIR3 interaction seems to be stronger for three smaller LexA/RAP1 hybrids (amino-terminal endpoints at 655, 667, and 679|, than for two longer protein fusions (endpoints at 647 and 653). However, the longest fusion tested [LexA/RAP1(635-827)] gives a value close to that of the three shorter hybrids. Because the RAPl-RIF1 interactions are constant, we imagine that the variability seen with $\mathrm{G}_{\mathrm{AD}}$ /SIR3 reflects a true difference in the interaction with this set of LexA/RAP1 hybrids rather than a variation in the amount or stability of the different hybrids (see below).

Next, we asked whether mutations in the RAPl carboxyl terminus also affect protein-protein interactions detected by the two-hybrid system. To do this, we used LexA/RAP1 hybrids with amino-terminal fusion junctions at amino acids $647,653,655,667$, and 679 of RAP1. All of these LexA/RAPl hybrids fail to activate transcription by themselves and are affected slightly or not at all by carboxy-terminal mutations. Data in Table 3 show that incorporation of a small linker insertion mutation at amino acid 825 of RAP1 $\left(825^{*}\right)$, which results in the addition of 5 amino acids very near the carboxyl termi- 
Table 3. A carboxy-terminal mutation of RAP1 weakens the interactions of LexA/RAP1 hybrids with $G_{A D} / S I R 3$ and $G_{A D} / R I F 1$

\begin{tabular}{lcr}
\hline $\begin{array}{l}\text { Mutant DNA-binding } \\
\text { domain hybrid }\end{array}$ & $\mathrm{G}_{\mathrm{AD}} / \mathrm{SIR} 3$ & $\mathrm{G}_{\mathrm{AD}} / \mathrm{RIF} 1$ \\
\hline LexA/RAP1 $\left(647-825^{\star}\right)$ & $258(1.3)$ & $2033(3.3)$ \\
LexA/RAP1 $\left(653-825^{\star}\right)$ & $349(1.6)$ & $1644(3.8)$ \\
LexA/RAP1 $\left(655-825^{\star}\right)$ & $163(5.4)$ & $1703(3.0)$ \\
LexA/RAP1 $\left(667-825^{\star}\right)$ & $156(23)$ & $26(263)$ \\
LexA/RAP1 $\left(679-825^{\star}\right)$ & $123(38)$ & $3(2125)$ \\
\hline
\end{tabular}

The first value given in each entry is the number of $\beta$-gal units measured for the interaction. The number in parenthesis is the fold decrease relative to the value obtained with the corresponding wild-type LexA/RAPl hybrid (i.e., not containing the $825^{*}$ mutation).

nus, reduces the ability of these hybrids to interact with $\mathrm{G}_{\mathrm{AD}} / \mathrm{SIR} 3$ and $\mathrm{G}_{\mathrm{AD}} / \mathrm{RIF} 1$. It should also be noted that the $825^{\star}$ mutation renders both the SIR3 and RIF1 interactions more dependent on amino-terminal sequences in the LexA/RAP1 hybrids. We have also tested carboxyterminal truncations of RAP1 for their ability to interact with $\mathrm{G}_{\mathrm{AD}} / \mathrm{SIR} 3$. Although these hybrids are weak activators themselves [e.g., LexA/RAPl(647-799) and LexA/ RAP1(653-799)], their activity is unchanged by the presence of $\mathrm{G}_{\mathrm{AD}} / \mathrm{SIR} 3$, suggesting that they fail to interact with this hybrid (data not shown).

\section{Mutation of SIR2, SIR3, SIR4, or RIF1 increases the transcriptional activation potential of LexA/RAP1 hybrids}

Previous studies of a series of GAL4 DNA-binding domain/RAPl hybrids had identified a transcriptional activation domain in RAPl (between amino acids 630 and 695) that partially overlaps its carboxy-terminal silencing domain (Hardy et al. 1992a). We reasoned that if the native SIR proteins do interact directly with the carboxyl terminus of RAP1 they might modulate its ability to function as a transcriptional activator. To test this idea, we examined the activation properties of a related series of LexA/RAPl hybrid proteins in strain CTY10-5D, which contains a LexA operator-lac $Z$ reporter gene, and each of five different derivatives of this strain containing gene disruptions of either SIR1, SIR2, SIR3, SIR4, or RIF1.

LexA/RAP1 hybrids that have amino-terminal endpoints at amino acids 562 and 630 have an increased ability to activate transcription of the reporter gene in sir3, sir4, and rif1 mutants (Fig. 3, rows 1 and 2). The level of $\beta$-galactosidase activity in these strains is increased 2- to 3.5-fold compared with that of wild-type cells. The next hybrid in the series, LexA/RAP1/635827), shows a particularly striking effect. This hybrid is unable to activate transcription of the reporter gene in wild-type cells but is converted into an activator in four of the mutant strains tested (Fig. 3, row 3). The $\beta$-galactosidase levels increase 7 -fold in the sir2 mutant, 16-fold in the rif 1 mutant, and almost 30 -fold in the sir 3 and sir 4 mutants relative to the $\mathrm{SIR}^{+} R I F^{+}$reporter strain. It is interesting to note that a sir 1 mutation had no effect on this or any other hybrid tested. Hybrids with RAP1 amino-terminal endpoints at amino acids 647 and 653 did not activate transcription in any genetic background tested (Fig. 3, rows 4 and 5), nor did shorter hybrids with endpoints at amino acids $655,667,679,691$, or 702 (data not shown). The effect of the sir2, sir3, sir4, and rif1 mutations on LexA/RAP1 hybrids appears to be specific as no effect is observed with two different and unrelated transcriptional activators, LexA/GAL4 (Fig. 3, bottom) and LexA/SNF6 (data not shown).

\section{Mutation of the RAP1 carboxyl terminus increases activation by LexA/RAP1 hybrids and abolishes SIR and RIF1 repression}

Taken together, the results described above suggest that the repressing effect of SIR and RIF1 genes on RAPl

\section{DNA-Binding Domain Hybrid}

Fold increase in mutant cells Activation in
Wild-Type Cells
( $\beta$-gal Units)

$\begin{array}{llllll} & \text { sir1 } & \text { sir2 } & \text { sir3 } & \underline{\text { sir4 }} & \underline{\text { rif1 }} \\ 283 & 0.8 & 1.3 & 2.0 & 1.9 & 2.6 \\ 363 & 0.9 & 1.1 & 2.0 & 2.9 & 3.5 \\ 6.0 & 1.1 & 7.0 & 28 & 27 & 16 \\ 2.0 & 1.0 & 0.9 & 1.1 & 1.3 & 1.1 \\ 2.0 & 1.0 & 1.0 & 0.8 & 1.1 & 1.0 \\ 10,000 & 1.0 & 1.0 & 1.0 & 1.0 & 1.0\end{array}$

Figure 3. Transcriptional activation by Lex/ RAP1 hybrids is increased by mutations in SIR2, SIR3, SIR4, and RIF1. Transcriptional activation measured in $\beta$-gal units in wildtype cells $(\mathrm{CTY} 10-5 \mathrm{D})$ is normalized to a value of 10,000 units for LexA/GAL4(768-881) [(LexA/G $\mathrm{G}_{\mathrm{AD}}$ )], which was included as a control in all experiments. Values for the hybrids in mutant cells are expressed as a fold increase over that in wild-type cells and are normalized to a value of 10,000 units for LexA/G $G_{A D}$ in that strain. LexA/ $G_{A D}$ values in all mutant strains were essentially indistinguishable from the wild-type parent. 
hybrids is attributable to a direct interaction between the SIR and RIFl proteins and the RAPl carboxyl terminus. A prediction of this model is that carboxy-terminal mutations in RAPl might increase the activation potential of some hybrids and relieve SIR and RIF repression. To test this idea, we introduced carboxy-terminal mutations into the series of hybrids shown in Figure 2. As shown in Figure 4, the $825^{*}$ linker-insertion mutation causes an 8 - and 10 -fold increase in the activation potential of hybrids with amino-terminal endpoints at positions 562 and 630, respectively. The same insertion mutation has an even more dramatic effect on the LexA/ RAP1(635-827) hybrid, increasing its ability to activate transcription by $>200$-fold. In contrast, the $825^{\star}$ mutation has no effect on hybrids beginning at amino acids 647 or 653 , both of which still fail to activate the reporter gene. It is worth noting that the wild-type versions of these two hybrids (LexA/RAP1(647-827) and LexA/ RAP1(653-827)] were also unaffected by sir and rif1 mutations (Fig. 3). A similar pattern is seen with LexA/ RAP1 hybrids truncated at amino acid 799 of RAP1 (Fig. 4 , bottom). In this case, however, hybrids beginning at amino acids 647 and 653 are partially activated by the 28-amino-acid truncation mutation. To ask whether any of the carboxy-terminal mutant LexA/RAPl hybrids (Fig. 4) are subject to repression by SIR or RIF1 proteins, we examined their activation properties in the series of

\section{DNA-Binding Domain Hybrid}

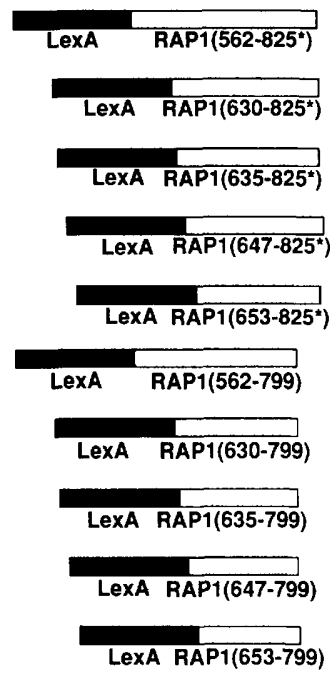

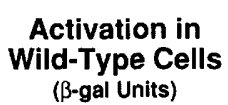

2235

3678

1395

2

2

1642

5207

3641

60

110
Fold Increase over Wild-type

7.9

10.1

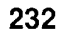

1.0

1.0

5.8

14.3

607

30

55
Figure 4. Transcriptional activation by LexA/RAP1 hybrids is increased by mutation of the RAPl carboxyl terminus. A series of LexA/RAP1 hybrids with different amino-terminal RAPl fusion endpoints (see Fig. 2) and either a linker insertion mutation two amino acids before the carboxyl terminus of RAP1 $\left(825^{*}\right)$ or a truncation of the carboxyl terminus at amino acid 799 were assayed as before (Fig. 2). The fold increase in activation compared to the corresponding hybrids with no mutation at the carboxyl terminus (see Fig. 2) is given in the right-hand column. mutant strains described above. Unlike the wild-type hybrids, none of the carboxy-terminal mutant hybrids were affected by mutations in $\operatorname{sir} 1, \operatorname{sir} 2, \operatorname{sir} 3$, sir 4 , or rif1 (data not shown).

\section{RAP1-SIR3, SIR3-SIR3, and SIR4-SIR3 interactions do not require endogenous SIR proteins}

The simplest explanation for the genetic results described above is that RAP1, SIR3, and SIR4 interact directly with one another. This notion is strongly supported in the case of the RAP1-SIR3 interaction, as biochemical experiments show that these two proteins can interact in vitro in the absence of other yeast proteins. However, it is possible that some or all of the two-hybrid interactions that we observe in vivo require the mediation of other SIR proteins or are modulated in some way by SIR proteins. To test this possibility we used derivatives of the CTY10-5D reporter strain described above, which contain mutations of SIR1, SIR2, SIR3, or SIR4. The $S I R$ dependency of the interaction between RAP1 and SIR3 was analyzed by using LexA/RAP1 hybrids with amino-terminal endpoints at amino acids 647 and 653. The interactions between SIR 3 and itself and between SIR3 and SIR4 we tested by using the two LexA/ SIR3 hybrids (see Table 2) and the $\mathrm{G}_{\mathrm{AD}}$ /SIR hybrids isolated from the library screens (see Table 1). It has not been possible to extend this analysis to the interaction between RAP1 and SIR4, as the only hybrid that interacts with SIR4 [LexA/RAP1(635-827)] becomes active when SIR2, SIR3, or SIR4 are mutated (Fig. 3).

None of the two-hybrid interactions tested require $S I R$ gene function (data not shown). However, the interaction between RAP1 and $\mathrm{G}_{\mathrm{AD}}$ /SIR3 appears to be slightly weakened by the absence of SIR2, particularly in the case of the longer LexA/RAP1 hybrids where $\beta$-galactosidase levels in the sir2 mutant are $40-50 \%$ that of wild type (data not shown). We conclude from these results that the RAP1-SIR3, SIR3-SIR3, and SIR4-SIR3 interactions detected by the two-hybrid assay are either direct or require the activity of other genes that we have not tested. It is worth emphasizing that a rather small carboxy-terminal domain of SIR4, consisting of only 97 amino acids, appears to be sufficient to confer both self-association and binding to SIR3, as both interactions are independent of endogenous SIR gene function. At present, we cannot rule out the possibility that RAP1 mediates these SIR interactions.

\section{RIF1 and SIR3 compete for binding to the carboxyl terminus of RAP1}

It has been shown recently that SIR proteins and RIF1 may have opposing functions with respect to telomere position effect and length regulation (Kyrion et al. 1993; Palladino et al. 1993). Here, we have shown that both SIR3 and RIF1 interact with a common set of LexA/ RAPl hybrid proteins in the two-hybrid system (Fig. 2). We therefore decided to ask whether RIFl competes with SIR3 for binding to the RAPl carboxyl terminus. To test 
this possibility we examined the interaction between $\mathrm{G}_{\mathrm{AD}} / \mathrm{SIR} 3$ and a series of LexA/RAP1 hybrids in a strain containing a disruption of the RIF1 gene. As shown in Table 4, the interaction between $\mathrm{G}_{\mathrm{AD}}$ /SIR3 and LexA/ RAP1 hybrids with amino-terminal endpoints between amino acids 647 and 655 appears to be stronger in rif1 mutant cells than in the isogenic $R I F 1^{+}$parent strain. Furthermore, the variability in the strength of the RAP1-SIR3 interaction is abolished, with the level of $\beta$-galactosidase reaching a nearly constant value of $-5000-6000$ units. Only the interaction with the shortest hybrid tested [LexA/RAP1 $(679-827)]$ is unaffected by the rif1 mutation. These results suggest that the native SIR3 and RIF1 proteins might compete for binding to the RAPl carboxyl terminus.

\section{Mutations in the RAP1 carboxyl terminus that diminish SIR3 binding affect silencing at HMR and at telomeres}

We have shown above that mutations in the carboxyl terminus of RAP1 affect the ability of LexA/RAPl hybrids to interact with SIR3 in the two-hybrid system (Table 3). If this putative RAP1-SIR3 interaction is important for silencing in vivo, we would expect that the same carboxy-terminal mutations in the context of native RAP1 would lead to silencing defects. To test this idea, we constructed strains in which the only copy of RAP1 contained one of four different carboxy-terminal mutations. These strains also contain either a TRP1 reporter gene under control of the $H M R-E$ silencer, or a $U R A 3$ gene adjacent to a telomere created at the $A D H 4$ locus (Gottschling et al. 1990). Because the HMR-E silencer is a redundant regulatory element (Brand et al. 1987; Kimmerly et al. 1988), we also tested a TRP1 reporter strain carrying a mutation in the ACS (A element) or the ABF1 site (B element) at the silencer. The $h m r \Delta \mathrm{A}$ silencer is particularly sensitive to mutations in RAP1 (Sussel and Shore 1991; Sussel et al. 1993). Silencing of the telomeric $U R A 3$ gene was monitored by assaying for growth in the presence of 5-fluoro-orotic acid (FOA), which kills cells expressing $U R A 3$.

In strains containing the rap1-7 mutation (a linker insertion at amino acid 825 , referred to earlier as $825^{*}$ ) a very slight defect is observed in silencing at $H M R$, as indicated by some growth in the absence of tryptophan,

Table 4. The RAP1-SIR3 interaction is improved by mutation of RIF1

\begin{tabular}{lccr}
\hline $\begin{array}{l}\text { DNA-binding } \\
\text { domain hybrid }\end{array}$ & $\begin{array}{l}\text { Activation } \\
\text { in wild-type } \\
\text { cells }\end{array}$ & $\begin{array}{l}\text { Activation } \\
\text { in rif1 } \\
\text { mutants }\end{array}$ & $\begin{array}{l}\text { Fold } \\
\text { increase }\end{array}$ \\
\hline LexA/RAP1 (647-827) & 325 & 4612 & 13.7 \\
LexA/RAP1 (653-827) & 487 & 5335 & 9.7 \\
LexA/RAP1 (655-827) & 878 & 5662 & 6.4 \\
LexA/RAP1 (667-827) & 3562 & 6124 & 1.7 \\
LexA/RAP1 (679-827) & 4680 & 5769 & 1.2 \\
\hline
\end{tabular}

All strains contain $\mathrm{G}_{\mathrm{AD}} /$ SIR3 (307-978). but only when the A element at HMR-E is mutated (Fig. 5A, row 3). However, the rap1-7 mutation causes a significant loss of telomeric silencing, as evidenced by a 1000-fold drop in FOA resistance in the strain containing a telomeric $U R A 3$ gene (Fig. 5B, row 3). More severe

A
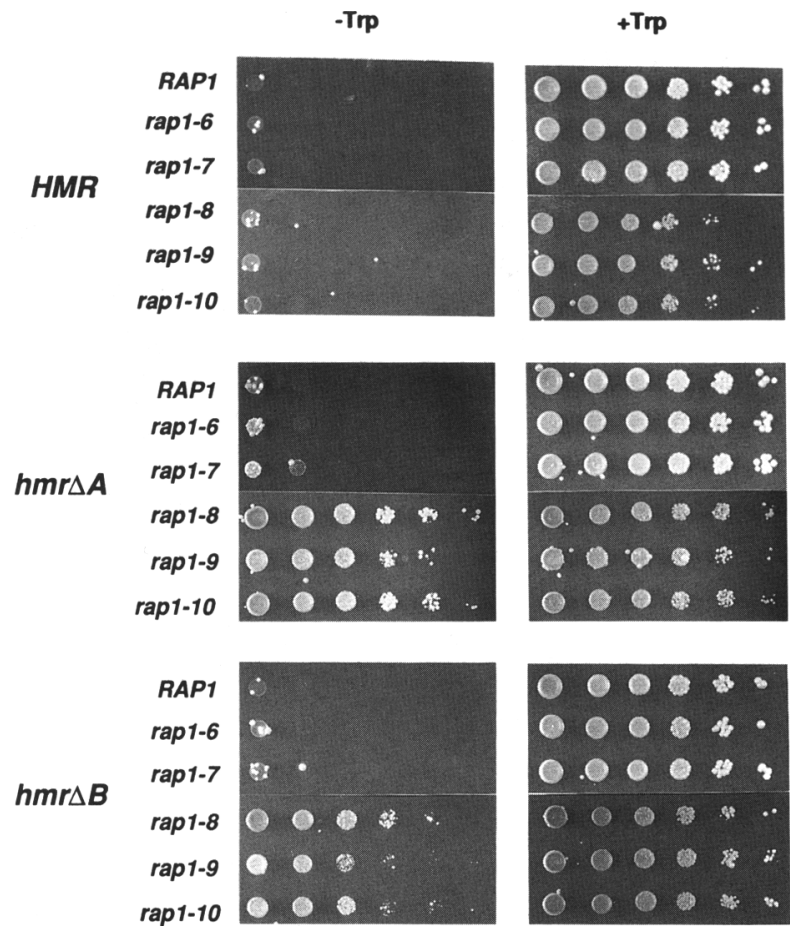

B

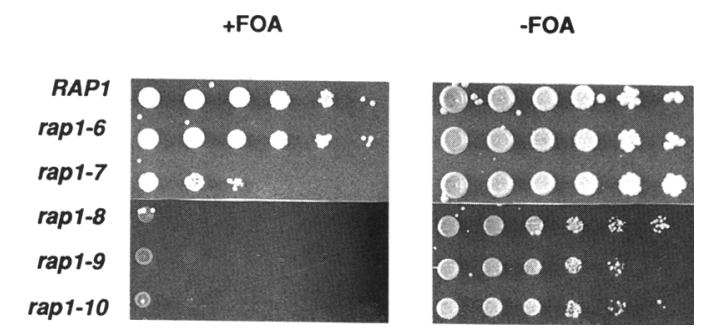

Figure 5. (A) Transcriptional silencing at the $H M R$ locus in $R A P 1$ and rap1 mutant strains. In all strains the TRP1 gene is present at $H M R$ together with either the wild-type $H M R-E$ silencer (top), an $H M R-E$ silencer with a mutated ACS (hmr $\Delta A$, middle), or an $H M R-E$ silencer with a mutated ABF1 DNAbinding site (hmr $\Delta B$, bottom). RAPl alleles: RAP1(1-827); rap16: RAP1( $443-279)$; rap1-7: RAP1(1-825*); rap1-8: RAP1(1-716); rap 1-9: RAP1(1-703); rap1-10: RAP1(1-695). Strains were grown overnight in rich medium, and sets of 10 -fold serial dilutions were spotted onto plates without $(-\operatorname{Trp})$ or with $(+\operatorname{Trp})$ tryptophan. Photographs were taken after 2-3 days of growth at $30^{\circ} \mathrm{C}$. (B) Transcriptional silencing at a telomere in RAP1 and rap1 mutant strains. In all of the strains shown, the $U R A 3$ gene is present adjacent to a telomere created at the $A D H 4$ locus on chromosome VIIL. A set of 10 -fold serial dilutions were spotted onto plates either with FOA or without the drug to monitor silencing of the telomeric URA3 gene. 
mutations of the RAPl carboxyl terminus, truncations at amino acids 716,703 , and 695 (rap1-8, rap1-9, and rap1-10, respectively) cause partial derepression of the $h m r \Delta B$ silencer and complete derepression of the $h m r \Delta A$ silencer (Fig. 5A, bottom two panels, rows 4-6). However, the wild-type $H M R-E$ silencer appears to be unaffected by these rap1 mutations (Fig. 5A, top panel, rows 4-6). All three of these RAP1 deletions also result in a complete loss of telomeric silencing (Fig. 5B, rows 4-6). An unrelated deletion of the amino terminus of RAP1 (rap1-6) shows no defect in either HMR or telomeric silencing, indicating the specificity of the carboxy-terminal deletions (Fig. 5A,B, row 2). Taken together, these data support the notion that the RAP1-SIR3 interaction is important for silencing, as there is a correlation between the strength of this interaction as measured by the two-hybrid system and the efficiency of repression at telomeres and RAP1-dependent silencers.

\section{Discussion}

\section{The role of RAP1 in transcriptional silencing}

Previous genetic studies have demonstrated the importance of the RAP1 carboxyl terminus in transcriptional silencing at $H M$ loci and telomeres (Kurtz and Shore 1991; Sussel and Shore 1991; Hardy et al. 1992a; Kyrion et al. 1993). The results reported here provide evidence for a molecular mechanism to explain the role of this RAP1 domain in silencing. We propose that RAP1 works at $H M$ silencers and at telomeres by recruiting a complex of SIR proteins via direct protein-protein interactions with its carboxyl terminus. This conclusion is based on four independent lines of evidence. First, SIR3 and SIR4 hybrid proteins interact with the RAPl carboxyl terminus in the two-hybrid system, and SIR3 can interact with both itself and SIR4. Second, SIR3 protein interacts with the RAPl carboxyl terminus in vitro in the absence of other yeast proteins. Third, mutation of the endogenous SIR genes increases the activation potential of RAPl in the context of LexA/RAPl hybrid proteins, providing independent evidence that the native SIR proteins can interact directly with the RAP1 carboxyl terminus. Finally, mutations in RAP1 that reduce or abolish the RAP1-SIR3 interaction in the two-hybrid system have a corresponding effect on silencing when incorporated into the native RAP1 protein. The ability of the RAP1 carboxyl terminus to bind SIR proteins may be sufficient to establish silencing, as hybrid proteins containing only this region of RAPl fused to the GAL4 DNA-binding domain can establish repression when targeted to mutated silencers containing GAL4 binding sites (S. Buck and D. Shore, unpubl.). We do not have enough information at present to know whether SIR4 interacts directly with either SIR3 or RAP1.

On the basis of the multiple interactions detected among RAP1, SIR3, and SIR4, we propose a model in which SIR3 and SIR4 form a heteromeric complex that interacts with RAP1 at $H M$ silencers and telomeres. The fact that both SIR3 and SIR4 (Chien et al. 1991) appear to interact with themselves and with each other suggests that these two proteins might be capable of forming a large complex containing at least two copies of each protein. One can also imagine that this putative SIR3-SIR4 complex is capable of initiating the assembly of a structure that extends along the chromatin fiber from silencers and telomeres. Such a polymerization model would provide an explanation for the ability of $H M$ silencers and telomeres to exert their repressive effects at a considerable distance. Results from previous studies are consistent with a structural role for SIR3 and SIR4, as both exhibit striking gene dosage effects. For example, excess SIR4 gene dosage or overexpression of a carboxyterminal fragment of the protein can interfere with silencing at HM loci and telomeres (Ivy et al. 1986; Marshall et al. 1987; Sussel and Shore 1991; Renauld et al. 1993). However, a single extra copy of SIR4 can suppress different silencing defects at HMR (Sussel et al. 1993). On the other hand, increased gene dosage of SIR3, but not SIR4, can increase the frequency of silencing and the extent of propagation of silent chromatin from telomeres (Renauld et al. 1993). Taken together, these data suggest that the precise roles of SIR3 and SIR4 may differ at both $H M$ loci and telomeres.

At present, the role of SIR2 in the putative RAP1-SIR complex is unclear. Mutations in SIR2 have only a modest effect on activation by LexA/RAPl hybrids compared with those of SIR3 and SIR4, and SIR2 was not identified in a two-hybrid screen for RAPl-interacting proteins. Perhaps SIR2 interacts with either SIR3, SIR4, or both proteins but does not contact RAP1 directly. It should be noted that the role of SIR2 in the cell is apparently different from that of either SIR3 or SIR4, as sir2 mutations affect $\mathrm{rDNA}$ recombination whereas mutations in either SIR3 or SIR4 do not (Gottlieb and Esposito 1989). The recent observation that overexpression of SIR2 results in histone deacetylation in vivo (Braunstein et al. 1993) suggests that SIR 2 may have a more direct role in modifying chromatin. One might imagine, therefore, that SIR2 is either loosely or transiently associated with a RAP1-SIR3/SIR4 complex or that SIR2 recognizes an altered chromatin conformation created by the action of this complex.

Data presented here raise the possibility that the native RIF1 and SIR3 proteins bind competitively to the RAPl carboxyl terminus. We interpret this result in terms of a model in which RIF1 binding to RAPl exerts a negative effect on silencing that primarily effects telomeres. Consistent with this model, rif1 mutants have been shown to display improved telomeric repression (Kyrion et al. 1993). Recent studies of rap $1^{s}$ mutants provide further support for this model and clarify the different roles of RAPl at HM loci and telomeres (S. Buck and D. Shore, unpubl.|.

\section{Protein-protein interactions and the context} dependence of RAP1 function

Previous studies clearly indicate that the regulatory function of RAP1 (either repression or activation) is de- 
termined by the context of its individual binding sites in the chromosome and, presumably, by different proteinprotein interactions (Shore and Nasmyth 1987; Buchman et al. 1988b). The work described here specifically suggests that such interactions occur at least in part at the carboxyl terminus of RAPl and may involve competitive binding between SIR proteins and components of the basal transcription machinery, regulatory proteins bound to nearby sites, or as yet unidentified coactivator proteins. We imagine that at promoters the RAPl carboxyl terminus interacts preferentially with proteins involved in transcriptional activation to the exclusion of SIR proteins. Conversely, at silencers and telomeres we imagine that RAP1-SIR interactions are favored with the result that RAP1 participates in repression (silencing).

Although the precise mechanism by which RAP1 interactions at $H M$ silencers, telomeres, and promoters are distinguished is unclear, a plausible model can be suggested from the available data. At HM silencers, a RAP1binding site is always found near an ACS, which is probably essential for the ability of RAP1 to promote silencing (Mahoney et al. 1991; McNally and Rine 1991; Rivier and Rine 1992). One possible role for the ACS and its complex of bound proteins (ORC) (Bell and Stillman 1992; Bell et al. 1993; Foss et al. 1993; Micklem et al. 1993) and ABF1 (Shore et al. 1987; Buchman et al. 1988a; Diffley and Stillman 1989a) is to help RAPl to efficiently bind SIR3 and SIR4 at $H M$ silencers, rather than factors involved in transcriptional activation. The SIRl protein, which does not appear to interact directly with RAPl, may participate in this process (Chien et al. 1993). The weaker effect of RAP1 carboxy-terminal mutations that we observe in the $h m r \Delta B$ strain, relative to the $h m r \Delta A$ strain, suggests that the A element makes a more important contribution to silencing in the absence of the RAP1 carboxyl terminus. When the ACS at HMR-E is mutated, we believe that the SIR1-dependent pathway is compromised so that mutations in RAP1 that diminish SIR binding have a more severe phenotype. The fact that the RAP1 carboxyl terminus and the RAP1-binding site at $H M R-E$ are not essential for silencing, yet SIR3 and SIR4 are, suggests that other silencer components are capable of recruiting the SIR3-SIR4 complex. At the telomere studied here, which does not contain either an ORC or an ABFl-binding site, we imagine that the numerous adjacent RAP1-binding sites within the $\mathrm{C}_{1-3} \mathrm{~A}$ repeats are themselves sufficient to allow for the cooperative assembly of a SIR3-SIR 4 complex through interactions with the RAP1 carboxyl terminus. Therefore, mutation of the RAPl carboxyl terminus results in a severe silencing defect at telomeres.

The best-characterized promoters containing RAP1binding sites are those of glycolytic enzyme genes. At these promoters RAPl appears to work together with another activator protein, the product of the GCR1 gene, to achieve full activation (Baker 1986; Tornow and Santangelo 1990). GCR1 itself is a sequence-specific DNAbinding protein (Baker 1991), and the presence of its binding site at many glycolytic gene promoters could explain its specific role in activation together with RAP1 at these genes. However, GCR1 appears to make a direct protein-protein interaction with RAPl and can function at some RAP1-containing promoters in the absence of its own DNA-binding domain (Tornow et al. 1993). Furthermore, it seems that not all GCR1-dependent promoters contain binding sites for this protein (Santangelo and Tornow 1990). The GAL11 protein also helps RAPl to activate at many different promoters yet does not appear itself to be a DNA-binding protein (Nishizawa et al. 1990). Therefore, protein-protein interactions between coactivators (e.g., GCR1 and GAL11) and RAPl may play an important role at many promoters. How these interactions are targeted to promoters without apparently interfering with the silencing function of RAPl at $H M$ loci and telomeres is not well understood.

Given the fact that RAP1 appears to be much more abundant than any of the SIR proteins (S.M. Gasser, pers. comm.l, it may seem surprising that deletion of $S I R$ genes can have such a profound effect on the activity of LexA/RAP1 hybrids. We suggest two reasons to account for these results. First, several of the LexA/RAPl hybrids that we have studied may have more inherently favorable interactions with silencing factors because of the absence of residues important for transcriptional activation. The particularly dramatic effect of sir and rif $1 \mathrm{mu}-$ tations on the LexA/RAP1(635-827) hybrid can thus be explained by the fact that this hybrid is actually missing only 5 amino acids from the amino terminus of the RAP1 activation domain. Second, it seems likely that the LexA operator-lac $Z$ reporter gene used in these studies provides a useful system to examine RAPl proteinprotein interactions precisely because it lacks auxiliary regulatory elements normally associated with RAP1binding sites at either promoters or $H M$ silencers. The presence of eight consecutive LexA operators upstream of the $l a c Z$ reporter gene may create a situation resembling that at telomeres, where consecutive RAP1-binding sites appear to favor interactions with SIR proteins. This feature of the artificial reporter may allow one to detect RAP1-SIR interactions that would not normally occur at natural promoters because of competition by other regulatory proteins bound to nearby sites or the action of coactivators that may themselves participate in other protein-protein interactions at promoters. By modifying this reporter gene system to include other regulatory elements found either at promoters or $H M$ silencers we may begin to obtain insights into the features of these elements that favor particular sets of RAPl protein-protein interaction at different chromosomal loci.

\section{RAP1 and nuclear localization of telomeres}

Recent studies have shown that yeast telomeres appear to be clustered in the nucleus and localized to the nuclear periphery, perhaps directly attached to the nuclear envelope (Klein et al. 1992). Strikingly, mutation of either SIR3 or SIR4 abolishes the perinuclear localization of telomeres and may also reduce their tendency to aggregate (Palladino et al. 1993). Our work provides a plausible molecular explanation for these observations. We 
suggest that the association of SIR3 and SIR4 with RAP1 protein bound to the terminal $\left(\mathrm{C}_{1-3} \mathrm{~A}\right)$ sequences at telomeres leads, either directly or indirectly, to their attachment to the nuclear membrane. The SIR complex may bind directly to the nuclear envelope via a carboxyterminal domain of SIR4 that is homologous to nuclear lamins (Diffley and Stillman 1989b). The ability of SIR3 and SIR4 to interact with themselves and each other may also explain the apparent aggregation of telomeres in vivo. Finally, attachment of RAP-bound chromosomal sequences to the nuclear membrane via a bound complex of SIR proteins may also explain the unusual segregation properties of plasmids containing either silencer elements or $\mathrm{C}_{1-3} \mathrm{~A}$ repeat sequences (Kimmerly and Rine 1987; Longtine et al. 1992, 1993).

\section{Materials and methods}

\section{Media and strains}

Growth and manipulation of yeast strains was done according to standard procedures (Rose et al. 1990). The yeast strain CTY10-5D (MATa ade2-1 trp1-901 leu2-3,112 his3-200 gal4 gal80 URA3:: lexA op-lacZ) was used in all studies involving LexA hybrid proteins. This strain la gift of C.-T.Chien and R. Sternglanz, State University of New York, Stony Brook) contains a lac $Z$ reporter gene with 4 ColEl operators (or eight binding sites for LexA dimers) inserted upstream of the transcription start site of a GAL1-lacZ gene integrated at the URA3 locus. HIS3 gene disruptions of SIR1, SIR2, SIR4 (Kimmerly and Rine 1987), SIR3, and RIF1 in strain CTY10-5D were obtained by gene replacement (Rothstein 1991) and confirmed by Southern blotting. The SIR3 disruption was constructed by deleting a BgIII-Xhol fragment (encoding amino acids 108-945) and replacing it with a fragment containing the HIS3 gene. The RIF1 disruption was constructed by replacement of an MluI-XbaI fragment of the gene with HIS3. This construct removes all of the amino-terminal RIF1-coding sequence, up to amino acid 1744. Libraries of partial Sau3A-digested yeast genomic DNA in the vectors pGAD1 and pGAD3 (Chien et al. 1991) were generously provided by P. Bartel and S. Fields (State University of New York, Stony Brook). Plasmid DNAs were rescued from CTY10-5D by transformation into the $E$. coli strain BAl $\mid$ thr leuB6 thi thy A trpC1117 hisB str ${ }^{\mathrm{R}}$, selecting simultaneously for ampicillin resistance and leucine prototrophy. Strains containing the rap1-6, rap1-7, rap1-8, rap1-9, and rap1-10 alleles are $M A T \alpha$ haploids in which the chromosomal copy of RAP1 is a rap1::LEU2 deletion/disruption that removes all of the RAP1 amino-terminal sequences up to amino acid 760 . The mutant rap1 allele is present in these cells on a HIS3 CEN plasmid. These strains are derived from a series of hmr::TRP1 strains or a URA3-Tel VIIL strain described previously (Sussel and Shore 1991; Chien et al. 1993). They are all otherwise isogenic to strain W303-1B (HML $\alpha$ MAT $\alpha$ HMRa ade2-1 can1-100 his311,15 leu2-3,112 trp1-1 ura3-1) (Thomas and Rothstein 1989).

\section{Plasmids}

The LexA protein and LexA/RAP1, LexA/SIR3, LexA/SIR4, and LexA/GAL4(768-881) hybrid proteins were expressed from plasmid pBTM1 $16(2 \mu$ origin, TRP1, pADH1-lexA; a gift of $P$. Bartel and S. Fields). Most RAP1 carboxy-terminal fragments were obtained from a set of $G_{B D} / R A P l$ fusions described previously (Hardy et al. 1992a) as EcoRI-PstI, BamHI-PstI, or SmaI-
PstI fragments. The RAP1(647-827) fragment was obtained from a XhoI linker insertion mutation. The RAP1(679-827) and RAP1(691-827) fragments were created by digestion at a BstBI or HindIII site in RAP1, respectively, followed by Klenow fragment repair of the ends. The carboxy-terminal deletion of RAPl at amino acid position 799 was generated by digestion at a $B c / I$ site followed by Klenow fragment repair of the end. LexA/ GAL4(768-881) (LexA/G $\mathrm{G}_{\mathrm{AD}}$ ) was constructed by cloning an EcoRI-BamHI fragment from pGAD3 (Chien et al. 1991), which contains the GAL4 activation domain (amino acids 768-881), into EcoRI-BamHI-cut pBTM116. LexA/SNF6 was a gift of B. Laurent (Laurent and Carlson 1992). The carboxy-terminal mutation of RAPl at amino acid position 825 was obtained by digestion at a Eco0109I site, followed by Klenow fragment repair of the ends and insertion of a 12-mer XhoI linker. The LexA/ SIR3(2-978) fusion was created by a three-way ligation in which an ECORI-ClaI fragment of SIR3 generated by PCR (a generous gift of C.-T. Chien) was ligated to a ClaI-BamHI fragment of the gene. The LexA/SIR3(307-978) fusion was created by joining SIR3 sequences ( $B g I I I-B a m H I)$ coding for amino acids 307-978 to LexA sequences in pBTM116. The LexA/SIR4(839-1358) and (1252-1358) fusions were created by ligating EcoRI-SalI fragments from plasmids pCTC17 and pCTC23 (Chien et al. 1991) into EcoRI-SalI-cut pBTM116. In some cases, the reading frame at the fusion junction of the pBTM116 plasmid was altered by filling in the EcoRI and BamHI sites within the polylinker of this vector. More detailed information about these constructs is available upon request.

Constructs for plasmid shuffling of rap1 mutant alleles were created using the pRS313 vector (Sikorski and Hieter 1989). Plasmids expressing the rap1 alleles 6-10 were constructed from a series of XhoI linker insertion mutations cloned into pRS313. Plasmids expressing the rap1-8, rap1-9, and rap1-10 alleles contain the $A D H 1$ terminator in place of the RAP1 terminator.

GST/RAP1 fusions were created in a version of the plasmid pGEX2TK in which the polylinker of the vector has been substituted with the polylinker of plasmid pIC20R (Marsh et al. 1984). The RAP1 carboxy-terminal fragments were obtained from a set of $\mathrm{G}_{\mathrm{BD}}$ / RAPl fusions described previously (Hardy et al. 1992a). The pT7-SIR3 construct has been made in plasmid pT7 $\beta$ SalI, by using a version of the SIR3 gene in which a $N$ coI site has been created at codon 1 . The PT7-RAP1 was made by site-directed mutagenesis of the RAP1 ATG to introduce a NcoI site followed by cloning of a NcoI-XbaI fragment into pT7 $\beta S a l I$ (Brigati et al. 1993).

Isolation and identification of SIR3 and SIR4 using the twohybrid system

The yeast LexA operator-lacZ reporter strain CTY10-5D was cotransformed with a plasmid expressing the LexA/RAPl/635827) hybrid and a library of genomic DNA fragments in the pGAD3 or pGAD1 expression vectors, using the high-efficiency transformation method of Schiestl and Geitz (1989). Transformants were selected on SC-Trp-Leu medium at $30^{\circ} \mathrm{C}$ and screened for $\beta$-galactosidase activity using a nitrocellulose filter assay (Breeden and Nasmyth 1985). Positive (blue) colonies were identified, purified, and retested. DNA prepared from positive clones was transformed into the Leu ${ }^{-}$E. coli strain BA1, and $\mathrm{Amp}^{\mathrm{R}} \mathrm{Leu}^{+}$transformants were selected. Plasmid DNA was tested by transformation into the yeast reporter strain CTY10-5D containing no plasmid, the LexA/RAP1(635-827) plasmid, or one of three different control plasmids expressing LexA, LexA-lamin, or LexA-ADH1 hybrids. Clones that displayed LexA/RAP1(635-827)-dependent activation were sub- 
jected to dideoxynucleotide sequencing using an oligonucleotide primer that hybridizes to the GAL4 activation domain sequences near the cloning junction $15^{\prime}$-TACCACTACAATGGATG-3').

\section{Transcriptional activation assays}

Transcriptional activation by LexA hybrids or LexA and $G_{A D}$ hybrid combinations was measured in strain CTY10-5D and its sir or rif1 mutant derivatives. Transformants were grown in selective liquid medium containing $0.05 \%$ glucose for $40 \mathrm{hr}$. Cells $(5 \mathrm{ml}$ ) were pelleted, resuspended in $250 \mu$ l of $\mathrm{Z}$ buffer $(60$ $\mathrm{mM} \mathrm{Na}_{2} \mathrm{HPO}_{4}, 40 \mathrm{mM} \mathrm{NaH}_{2} \mathrm{PO}_{4}, 10 \mathrm{mM} \mathrm{KCl}$, and $1 \mathrm{mM} \mathrm{MgSO}_{4}$ ) containing $0.27 \% \quad \beta$-mercaptoethanol, and permeabilized by $3 \times 1 \mathrm{~min}$ of rapid vortexing with 0.3 gram of glass beads. The suspension was centrifuged and $20-150 \mu \mathrm{l}$ of the supernatant was used in a 1-ml $\beta$-galactosidase assay (Miller 1972; Breeden and Nasmyth 1987). Activities were normalized to protein concentration using the Bradford assay (Bradford 1976). Units of $\beta$-galactosidase activity were calculated by taking the average from at least three independent transformants of each construct. Values for independent transformants varied from each other by $<20 \%$. All numbers reported for LexA/RAPl hybrids have been normalized by using a value of 10,000 units for LexA/ $\mathrm{G}_{\mathrm{AD}}$ in that strain. Activation by $\operatorname{LexA} / \mathrm{G}_{\mathrm{AD}}$ in sir and rif1 mutants was essentially indistinguishable from that seen in the wild-type CTY10-5D parent strain.

\section{In vitro protein-binding studies}

GST/RAP1 fusion proteins were expressed in E. coli strain $\mathrm{DH} 5 \alpha$. Transformants were grown overnight in $10 \mathrm{ml}$ of $2 \mathrm{XTY}$ medium containing $50 \mu \mathrm{g} / \mathrm{ml}$ of ampicillin, pelleted, grown for $3 \mathrm{hr}$ in $50 \mathrm{ml}$ of fresh medium, and induced for $1.5 \mathrm{hr}$ with isopropyl- $\beta$-D-thiogalactopyranoside (IPTG) at $0.1 \mathrm{~mm}$. The cells were then pelleted and resuspended in $1 \mathrm{ml}$ of TEN buffer (100 $\mathrm{mM}$ Tris- $\mathrm{HCl}$ at $\mathrm{pH} 7.4,1 \mathrm{~mm}$ EDTA, $50 \mathrm{~mm} \mathrm{NaCl}$ ) containing $1 \mathrm{mM}$ phenylmethylsulfonylfluoride (PMSF) and $20 \mu \mathrm{g} / \mathrm{ml}$ of pepstatin A, and sonicated on ice for $15 \mathrm{sec}$. Insoluble material was pelleted at $10,000 \mathrm{rpm}$ for $10 \mathrm{~min}$ in a Sorvall SS34. Supernatants were stored at $-70^{\circ} \mathrm{C}$ or used immediately for adsorption on glutathione-agarose.

Typical binding reactions used $400 \mu \mathrm{l}$ of crude bacterial extracts and $200 \mu \mathrm{l}$ of glutathione-agarose slurry incubated at $4^{\circ} \mathrm{C}$ for $1 \mathrm{hr}$ on a rocking platform. The agarose beads were washed five times with $1 \mathrm{ml}$ of TEN buffer and resuspended in $100 \mu \mathrm{l}$ of TEN buffer to obtain a $50 \%$ slurry. An aliquot $(10 \mu l)$ of each purified fusion protein was diluted in an equal volume of $2 \times$ SDS sample buffer and analyzed by $10 \%$ SDS-PAGE. Gels were stained with Coomassie blue.

SIR3 protein was synthesized in vitro using the TNT T7coupled reticulocyte lysate system (Promega) according to the manufacturer's instructions. An aliquot $(5 \mu l)$ of the reaction was diluted with $20 \mu \mathrm{l}$ of SDS sample buffer, heated for $3 \mathrm{~min}$ in boiling water, and analyzed by SDS-PAGE. The gels were treated with fixing solution for $30 \mathrm{~min}$ and Amplify (Amersham International) for $30 \mathrm{~min}$, and then dried and exposed to X-ray film.

Typical protein-binding reactions were performed in $200 \mu \mathrm{l}$ of binding buffer (20 mM HEPES at pH 7.5, 1 mM EDTA, $25 \mathrm{~mm}$ $\mathrm{NaCl}, 7 \mathrm{mM} \mathrm{MgCl} 2,0.05 \% \mathrm{NP}-40,17 \%$ glycerol), containing 20 $\mu \mathrm{l}$ of purified GST-RAPl protein adsorbed to the $50 \%$ glutathione-agarose slurry (in binding buffer). The beads were preincubated with $100 \mu \mathrm{g} / \mathrm{ml}$ of BSA for $15 \mathrm{~min}$, and incubated with 3 $\mu \mathrm{l}$ of in vitro-synthesized proteins for $1 \mathrm{hr}$. The beads were collected with a 5-sec pulse in a microcentrifuge and washed three times with $1 \mathrm{ml}$ of binding buffer. Washed beads were resuspended in $30 \mu$ lof $2 \times$ SDS sample buffer, heated for $3 \mathrm{~min}$ in boiling water, and analyzed by SDS-PAGE. The gels were treated and exposed to X-ray film as before.

\section{Acknowledgments}

We thank Paul Bartel and Stan Fields for the generous gift of pGAD libraries and helpful discussions during early phases of this work; Chien-Ting Chien, Rolf Sternglanz, and Brehon Laurent for strains and plasmids; members of the Shore laboratory for many useful discussions; Aaron Mitchell, Hamish Young, and Serge Gangloff for helpful comments on the manuscript. This work was supported by grants from the National Institutes of Health (NIH) (GM40094), the American Cancer Society (VM62 and MV-534), and the Irma T. Hirschl Charitable Trust to D.S. K.F. was a postdoctoral trainee on an NIH Cancer Biology grant (CA09503-0). P.M. is a doctoral candidate in Molecular and Cellular Biology and Pathology at the University of Padova, Italy.

The publication costs of this article were defrayed in part by payment of page charges. This article must therefore be hereby marked "advertisement" in accordance with 18 USC section 1734 solely to indicate this fact.

\section{References}

Aparicio, O.M., B.L. Billington, and D.E. Gottschling. 1991. Modifiers of position effect are shared between telomeric and silent mating-type loci in S. cerevisiae. Cell 66: 12791287.

Baker, H.V. 1986. Glycolytic gene expression in Saccharomyces cerevisiae: Nucleotide sequence of GCR1, null mutants, and evidence for expression. Mol. Cell. Biol. 6: 3774-3784.

- 1991. GCR1 of Saccharomyces cerevisiae encodes a DNA binding protein whose binding is abolished by mutations in the CTTCC sequence motif. Proc. Natl. Acad. Sci. 88: 9443-9447.

Bell, S.P. and B. Stillman. 1992. ATP-dependent recognition of eukaryotic origins of DNA replication by a multiprotein complex. Nature 357: 128-134.

Bell, S.P., R. Kobayashi, and B. Stillman. 1993. Yeast origin recognition complex functions in transcripton silencing and DNA replication. Science 262: 1844-1849.

Bitter, G.A., K.K.H. Chang, and K.M. Egan. (1991). A multicomponent upstream activation sequence of the Saccharomyces cerevisiae glyceraldehyde-3-phosphate dehydrogenase gene promoter. Mol. \& Gen. Genet. 231: 22-32.

Bradford, M. 1976. A rapid and sensitive method for the quantitation of microgram quantities of protein utilizing the principle of protein-dye binding. Anal. Biochem. 72: 248254.

Brand, A.H., G. Micklem, and K. Nasmyth. 1987. A yeast silencer contains sequences that can promote autonomous plasmid replication and transcriptional activation. Cell 51: 709-719.

Braunstein, M., A.B. Rose, and S.G. Holmes. 1993. Transcriptional silencing in yeast is associated with reduced nucleosome acetylation. Genes \& Dev. 7: 592-604.

Breeden, L. and K. Nasmyth. 1985. Regulation of the yeast $H O$ gene. Cold Spring Harbor Symp. Quant. Biol. 50: 643-650.

- 1987. Cell cycle control of the yeast HO gene: Cis- and trans-acting regulators. Cell 48: 389-397.

Brigati, C., S. Kurtz, D. Balderes, G. Vidali, and D. Shore. 1993. 
An essential yeast gene encoding a TTAGGG repeat-binding protein. Mol. Cell. Biol. 13: 1306-1314.

Buchman, A.R., W.J. Kimmerly, J. Rine, and R.D. Kornberg. 1988a. Two DNA-binding factors recognize specific sequences at silencers, upstream activating sequences, autonomously replicating sequences, and telomeres in Saccharomyces cerevisiae. Mol. Cell. Biol. 8: 210-225.

Buchman, A.R., N.F. Lue, and R.D. Kornberg. 1988b. Connections between transcriptional activators, silencers, and telomeres as revealed by functional analysis of a yeast DNAbinding protein. Mol. Cell. Biol. 8: 5086-5099.

Chambers, A., J.S.H. Tsang, C. Stanway, A.J. Kingsman, and S.M. Kingsman. 1989. Transcriptional control of the Saccharomyces cerevisiae PGK gene by RAP1. Mol. Cell. Biol. 9: $5516-5524$

Chien, C.-T., P.L. Bartel, R. Sternglanz, and S. Fields. 1991. The two-hybrid system: A method to identify and clone genes for proteins that interact with a protein of interest. Proc. Natl. Acad. Sci. 88: 9578-9582.

Chien, C.-T., S. Buck, R. Sternglanz, and D. Shore. 1993. Targeting of SIRl protein establishes transcriptional silencing at $H M$ loci and telomeres in yeast. Cell 75: 531-541.

Conrad, M.N., J.H. Wright, A.J. Wolf, and V.A. Zakian. 1990. RAPl protein interacts with yeast telomeres in vivo: Overproduction alters telomere structure and decreases chromosome stability. Cell 63: 739-750.

Diffley, J.F. and B. Stillman. 1989a. Similarity between the transcriptional silencer binding proteins ABF1 and RAP1. Science 246: 1034-1038.

1989b. Transcriptional silencing and lamins. Nature. 342: 24.

Fields, S. and O.K. Song. 1989. A novel genetic system to detect protein-protein interactions. Nature 340: 245-246.

Foss, M., F.J. McNally, P. Laurenson, and J. Rine. 1993. Origin recognition complex (ORC) in transcriptional silencing and DNA replication in S. cerevisiae. Science 262: 1838-1844.

Gilson, E., M. Roberge, R. Giraldo, D. Rhodes, and S.M. Gasser. 1993. Distortion of the DNA double helix by RAP1 at silencers and multiple telomeric binding sites. I. Mol. Biol. 231: 293-310.

Gottlieb, S. and R.E. Esposito. 1989. A new role for a yeast transcriptional silencer gene, SIR2, in regulation of recombination in ribosomal DNA. Cell 56: 771-776.

Gottschling, D.E., O.M. Aparicio, B.L. Billington, and V.A. Zakian. 1990. Position effect at $S$. cerevisiae telomeres: Reversible repression of pol II transcription. Cell 63: 751-762.

Haber, J.E. and J.P. George. 1979. A mutation that permits the expression of normally silent copies of mating type information in Saccharomyces cerevisiae. Genetics 93: 13-35.

Hardy, C.F.J., D. Balderes, and D. Shore. 1992a. Dissection of a carboxy-terminal region of the yeast regulatory protein RAPl with effects on both transcriptional activation and silencing. Mol. Cell. Biol. 12: 1209-1217.

Hardy, C.F.J., L. Sussel, and D. Shore. 1992b. A RAP1-interacting protein involved in silencing and telomere length regulation. Genes \& Dev. 6: 801-814.

Huie, M.A., E.W. Scott, C.M. Drazinic, M.C. Lopez, I.K. Hornstra, T.P. Yang, and H.V. Baker. 1992. Characterization of the DNA-binding activity of GCR1: In vivo evidence for two GCRl-binding sites in the upstream activating sequence of TPI of Saccharomyces cerevisiae. Mol. Cell. Biol. 12: 26902700.

Ivy, J.M., A.J.S. Klar, and J.B. Hicks. 1986. Cloning and characterization of four SIR genes from Saccharomyces cerevisiae. Mol. Cell. Biol. 6: 688-702.

Johnson, L.M., P.S. Kayne, E.S. Kahn, and M. Grunstein. 1990.
Genetic evidence for an interaction between SIR3 and histone $\mathrm{H} 4$ in the repression of the silent mating loci in Saccharomyces cerevisiae. Proc. Natl. Acad. Sci. 87:62866290.

Kimmerly, W. and J. Rine. 1987. Replication and segregation of plasmids containing cis-acting regulatory sites of silent mating-type genes in Saccharomyces cerevisiae are controlled by the SIR genes. Mol. Cell. Biol. 7: 4225-4237.

Kimmerly, W., A. Buchman, R. Kornberg, and J. Rine. 1988. Roles of two DNA-binding factors in replication, segregation and transcriptional repression mediated by a yeast silencer. EMBO J. 7: 2241-2253.

Klar, A.J.S., S. Fogel, and K. McLeod. 1979. MAR1-A regulator of $H M \mathbf{a}$ and $H M \alpha$ loci in Saccharomyces cerevisiae. Genetics 93: 37-50.

Klein, F., T. Laroche, M.E. Cardenas, J.F.-X. Hofmann, D. Schweizer, and S.M. Gasser. 1992. Localization of RAP1 and topoisomerase II in nuclei and meiotic chromosomes of yeast. I. Cell. Biol. 117: 935-948.

Kurtz, S. and D. Shore. 1991. The RAP1 protein activates and silences transcription of mating-type genes in yeast. Genes \& Dev. 5: 616-628.

Kyrion, G., K.A. Boakye, and A.J. Lustig. 1992. C-terminal truncation of RAPl results in the deregulation of telomere size, stability, and function in Saccharomyces cerevisiae. Mol. Cell. Biol. 12: 5159-5173.

Kyrion, G., K. Liu, C. Liu, and A.J. Lustig. 1993. RAPl and telomere structure regulate telomere position effects in Saccharomyces cerevisiae. Genes \& Dev. 7: 1146-1159.

Laurent, B.C. and M. Carlson. 1992. Yeast SNF2/SWI2, SNF5, and SNF6 proteins function coordinately with the gene-specific transcriptional activators GAL4 and Bicoid. Genes \& Dev. 6: 1707-1715.

Longtine, M.S., N.M. Wilson, M.E. Petracek, and J. Berman. 1989. A yeast telomere binding activity binds to two related telomere sequence motifs and is indistinguishable from RAPl. Curr. Genet. 16: 225-240.

Longtine, M.S., S. Enomoto, S.L. Finstad, and I. Berman. 1992. Yeast telomere repeat sequence (TRS) improves circular plasmid segregation, and TRS plasmid segregation involves the RAP1 gene product. Mol. Cell. Biol. 12: 1997-2009.

Longtine, M.S., S. Enomoto, S.L. Finstad, and J. Berman. 1993. Telomere-mediated plasmid segregation in Saccharomyces cerevisiae involves gene products required for transcriptional repression at silencers and telomeres. Genetics 133: $171-82$.

Lustig, A.J., S. Kurtz, and D. Shore. 1990. Involvement of the silencer and UAS binding protein RAP1 in regulation of telomere length. Science 250: 549-553.

Mahoney, D.J., R. Marquardt, G.-J. Shei, A.B. Rose, and J.R. Broach. 1991. Mutations in the HML E silencer of Saccharomyces cerevisiae yield metastable inheritance of transcriptional repression. Genes \& Dev. 5: 605-615.

Marsh, J.L., M. Erfle, and E.J. Wykes. 1984. The pIC plasmid and phage vectors with versatile cloning sites for recombinant selection by insertional inactivation. Gene 32: 481-485.

Marshall, M., D. Mahoney, A. Rose, J.B. Hicks, and J.R. Broach. 1987. Functional domains of SIR4, a gene required for position effect regulation in Saccharomyces cerevisiae. Mol. Cell. Biol. 7: 4441-4452.

McNally, F.J. and J. Rine. 1991. A synthetic silencer mediates SIR-dependent functions in Saccharomyces cerevisiae. Mol. Cell. Biol. 11: 5648-5659.

Micklem, G., A. Rowley, J. Harwood, K. Nasmyth, and J.F.X. Diffley. 1993. Yeast origin recognition complex is involved in DNA replication and transcriptional silencing. Nature 
366: 87-89.

Miller, J.H. 1972. Experiments in molecular genetics. Cold Spring Harbor Laboratory, Cold Spring Harbor, New York.

Nishizawa, M., R. Araki, and Y. Teranishi. 1989. Identification of an upstream activating sequence and an upstream repressible sequence of the pyruvate kinase gene of the yeast Saccharomyces cerevisiae. Mol. Cell. Biol. 9: 442-451.

Nishizawa, M., Y. Suzuki, Y. Nogi, K. Matsumoto, and T. Fukasawa. 1990. Yeast Gall1 protein mediates the transcriptional activation signal of two different transacting factors, Gal4 and general regulatory factor I/repressor/activator site binding protein 1/translation upstream factor. Proc. Natl. Acad. Sci. 87: 5373-5377.

Palladino, F., T. Laroche, E. Gilson, A. Axelrod, L. Pillus, and S.M. Gasser. 1993. SIR3 and SIR4 proteins are required for the positioning and integrity of yeast telomeres. Cell 75: 543-555.

Pillus, L. and J. Rine. 1989. Epigenetic inheritance of transcriptional states in $S$. cerevisiae. Cell 59: 637-647.

Renauld, H., O.M. Aparicio, P.D. Zierath, B.L. Billington, S.K. Chhablani, and D.E. Gottschling. 1993. Silent domains are assembled continuously from the telomere and are defined by promoter distance and strength, and by SIR3 dosage. Genes \& Dev. 7: 1133-1145.

Rine, J. and I. Herskowitz. 1987. Four genes responsible for a position effect on expression from $H M L$ and $H M R$ in Saccharomyces cerevisiae. Genetics 116: 9-22.

Rine, J., J.N. Strathern, J.B. Hicks, and I. Herskowitz. 1979. A suppressor of mating-type locus mutations in Saccharomyces cerevisiae: Evidence for and identification of cryptic mating type loci. Genetics 93: 877-901.

Rivier, D.H. and J. Rine. 1992. An origin of DNA replication and a transcriptional silencer require a common element. Science 256: 659-663.

Rose, M.D., F. Winston, and P. Hieter. 1990. Methods in yeast genetics: A laboratory manual. Cold Spring Harbor Laboratory Press, Cold Spring Harbor, New York.

Rotenberg, M.O. and J.L.J. Woolford. 1986. Tripartite upstream promoter element essential for expression of Saccharomyces cerevisiae ribosomal protein genes. Mol. Cell. Biol. 6: 674687.

Rothstein, R. 1991. Targeting, disruption, replacement, and allele rescue: Integrative DNA transformation in yeast. Methods Enzymol. 194: 281-301.

Santangelo, G.M. and J. Tornow. 1990. Efficient transcription of the glycolytic gene $A D H 1$ and three translational component genes requires the GCR1 product, which can act through TUF/GRF/RAP binding sites. Mol. Cell. Biol. 10: $859-862$.

Schiestl, R.H. and R.D. Gietz. 1989. High efficiency transformation of intact yeast cells using single stranded nucleic acids as a carrier. Curr. Genet. 16: 339-346.

Shore, D. and K. Nasmyth. 1987. Purification and cloning of a DNA binding protein from yeast that binds to both silencer and activator elements. Cell 51: 721-732.

Shore, D., M. Squire, and K.A. Nasmyth. 1984. Characterization of two genes required for position effect control of mating type. EMBO I. 3: 2817-2823.

Shore, D., D.J. Stillman, A.H. Brand, and K.A. Nasmyth. 1987. Identification of silencer binding proteins from yeast: Possible roles in SIR control and DNA replication. EMBO $/$. 6: 461-467.

Sikorski, R. and P. Hieter. 1989. A system of shuttle vectors and yeast host strains designed for efficient manipulation of DNA in Saccharomyces cerevisiae. Genetics 122: 19-27.

Stone, E.M., M.J. Swanson, A.M. Romeo, J.B. Hicks, and R.
Sternglanz. 1991. The SIR1 gene of Saccharomyces cerevisiae and its role as an extragenic suppressor of several mating-defective mutants. Mol. Cell. Biol. 11: 2253-2262.

Sussel, L. and D. Shore. 1991. Separation of transcriptional activation and silencing functions of the RAP1-encoded repressor/activator protein 1 : Isolation of viable mutants affecting both silencing and telomere length. Proc. Natl. Acad. Sci. 88: 7749-7753.

Sussel, L., D. Vannier, and D. Shore. 1993. Epigenetic switching of transcriptional states: Cis- and trans-acting factors affecting establishment of silencing at the HMR locus in Saccharomyces cerevisiae. Mol. Cell. Biol. 13: 3919-3928.

Thomas, B.J. and R. Rothstein. 1989. Elevated recombination rates in transcriptionally active DNA. Cell 56: 619-630.

Tornow, J. and G.M. Santangelo. 1990. Efficient expression of the Saccharomyces cerevisiae glycolytic gene $A D H 1$ is dependent upon a cis-acting regulatory element (UAS $\left.S_{\mathrm{RPG}}\right)$ found initially in genes encoding ribosomal proteins. Gene 90: $79-85$.

Tornow, J., X. Zeng, W. Gao, and G.M. Santangelo. 1993. GCR1, a transcriptional activator in Saccharomyces cerevisiae, complexes with RAPl and can function without its DNA binding domain. EMBO J. 12: 2431-2437.

Vignais, M.-L., L.P. Woudt, G.M. Wassenaar, W.H. Mager, A. Sentenac, and R.J. Planta. 1987. Specific binding of TUF factor to upstream activation sites of yeast ribosomal protein genes. EMBO /. 6: 1451-1457. 


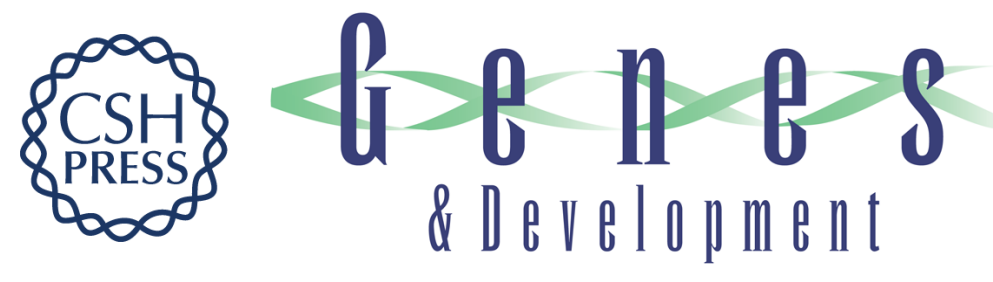

\section{Evidence that a complex of SIR proteins interacts with the silencer and telomere-binding protein RAP1.}

P Moretti, K Freeman, L Coodly, et al.

Genes Dev. 1994, 8:

Access the most recent version at doi:10.1101/gad.8.19.2257

References This article cites 71 articles, 41 of which can be accessed free at:

http://genesdev.cshlp.org/content/8/19/2257.full.html\#ref-list-1

License

Email Alerting

Service

Receive free email alerts when new articles cite this article - sign up in the box at the top right corner of the article or click here.

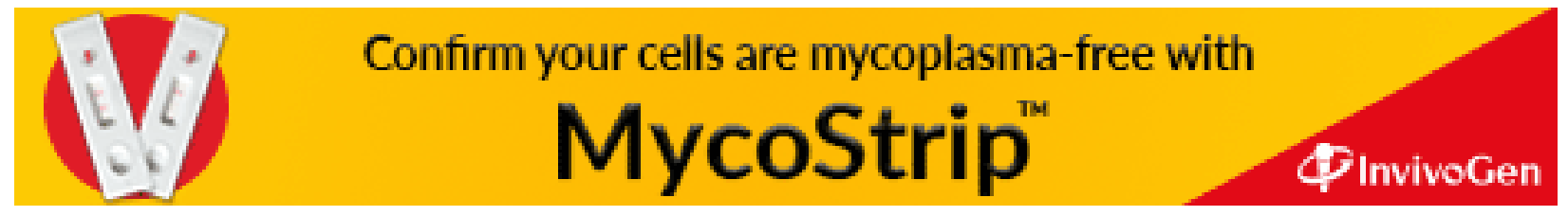

